bind the 1,678 pages into a single volume or even to bind them at all? At $\$ 10$ the book is a good buy, but a collection of separate articles would have been more comfortable to read than a volume measuring $28 \times 22 \times 6.5 \mathrm{~cm}$ and weighing nearly $5 \mathrm{~kg}$. Reference would be easier if the number of the chapter and the author's name had been put at the head of each page.

Though the organization of the book is unsatisfactory, one can be grateful for the new knowledge it contains. No rain forest has ever been studied so intensively as EI Verde. It is a pity that it requires the threat of nuclear disaster to make such a project possible.

\section{P. W. RICHARDS}

\section{Excitable Cells}

The Physiology of Excitable Cells. By D. J. Aidley. Pp. ix +468 . (Cambridge University: London, June 1971.) £5.80; $\$ 15$.

PERHAPS every scientist considers that the recent history of his own discipline is the best demonstration of the scientific method in operation. That many neurophysiologists are of this opinion is understandable after reading D. J. Aidley's book, The Physiology of Excitable Cells, for this is a collection of elegant and intellectually satisfying experiments and analyses which, taken as a whole, contribute greatly towards an understanding of the fundamental workings of the nervous system.

After a brief introduction which deals with the concepts and techniques particular to the electrophysiologist, the book can be divided into three principal sections. The first concerns the neurone and the structure and electrochemistry of the cell membrane, both in the resting condition and during the propagation of the action potential. This is followed by a consideration of the neuromuscular junction and the physiology and pharmacology of synaptic transmission. The second section develops the subject of muscular contraction, building up from the essential structure of the myofilament and the coupling of the processes of excitation and contraction, to a study of the activity of entire muscles. The third section begins with a statement of the general principles that apply to the functioning of sensory receptors and the principles are then illustrated by reference to special sensory systems. These systems are the acoustics-lateralis system of vertebrates, mammalian muscle spindles, insect chemoreceptors, electroreceptors and the vertebrate eye.

The scope of the author's approach is impressive and has certainly involved the unenviable task of assimilating a great variety and depth of source materials. The result is a text written in an economical style which develops the various themes in a logical and, for the most part, highly coherent way. The many mathematical arguments involved are well presented and adequately explained, the value of hypotheses is carefully weighed and the evidence for them is discussed in a good critical manner. In addition a genuine attempt has been made to develop a comparative approach so that various classical preparations, such as the squid giant axon, are placed in their proper comparative perspective and the inclusion of chapters on the electrical properties of glial cells and the physiology of the electric organs of fish enhances the impression of a well rounded account.

One small criticism is that the section on sense organs would not suffer from some expansion, nevertheless, this book more than fulfils its intention of being a course book for undergraduate students of neurophysiology and its comprehensive nature and critical style place it in favourable comparison with respect to other, and usually more restricted, works on the subject.

John A. Patrerson

\section{DMSO Re-evaluated}

Dimethyl Sulfoxide. Vol. 1: Basic Concepts of DMSO. By Stanley W. Jacob, Edward E. Rosenbaum and Don C. Wood. Pp. xv+479. (Dekker: New York, February 1971.) $\$ 27.50 ; £ 13.10$.

Heralded as a new "wonder-drug" in 1964 and then condemned as dangerously toxic in the following year, dimethyl sulphoxide (DMSO) has been one of the most controversial chemicals of modern times. Although first prepared nearly a century earlier by Alexander Saytzeff, it was Stanley Jacob's and Robert Herschler's discovery of its unique tissue penetrating powers and its diverse pharmacological activities which led to the widespread interest in DMSO, particularly for its use as a solvent vehicle which enhanced the percutaneous absorption of drugs and for the many potential clinical applications in human and veterinary medicine and in agriculture. But reports of toxic effects to the lens of the eye in experimental animals (which have not been reproduced in man or primates) led the US Food and Drug Administration to terminate promptly the clinical investigations on the drug which were just getting under way. Many scientists, particularly Drs Stanley Jacob and Chauncey Leake in the United States and Dr Gerhard Ludahn in Europe, held faith with the new drug and subsequent work has indeed shown that the early reports of toxicity may have been exaggerated and the cessation of clinical studies was perhaps unwarranted.

Some five or more years later, the initial over-enthusiastic acclaim of its potential as a drug and the following hasty condemnation have now given way to a more reasoned attitude with critical scientific evaluation replacing emotional subjective opinion, and the possible clinical uses of this interesting compound are being re-examined. The time was therefore most opportune for the publication of this evidence in its entirety and this is the stated intention of the editors of this encyclopaedic monograph on DMSO. In this first volume Stanley Jacob and his colleagues Edward Rosenbaum and Don C. Wood have brought together their own extensive published work on the subject and, along with that of many collaborators, have produced an impressive work of reference which covers the chemistry, biochemistry, pharmacology and toxicology of DMSO together with its radioprotective and cryoprotective properties and its uses in enzymology, microbiology, immunology, dermatology and veterinary medicine. This was no small task, for the published literature on DMSO is extensive, as may be adjudged from the number of references cited, which is well over two thousand. Somewhat regrettably, however, there is duplication of many of these in the last chapter entitled "DMSO Bibliography" which, for no stated reason, is confined to cryobiology, chemistry and pharmacology.

Nevertheless, this is an outstanding work of dedication by scientists and clinicians who believe in the future of DMSO. It is excellently presented and lucidly written and it will form the standard work of reference of the subject for biomedical scientists of all disciplines. The second volume of this monograph will contain reviews of the clinical studies on DMSO and it is to be hoped will present some of the most vital evidence of this controversy and thus complete the case for the reinstatement of DMSO as a useful agent in clinical medicine.

Dennis V. Parke

\section{Camera in the Gut}

The Digestive System. By P. G. Toner, K. C. Carr and G. M. Wyburn. Pp. $x+303$. (Butterworth: London, July 1971.) $£ 10$.

THIs book presents a timely synthesis of form and function in the alimentary tract and should have a wide appeal not only to basic scientists but also to gastroenterologists who seek a cellular background to their speciality. Written by a pathologist and two anatomists, the book surveys the normal cellular anatomy of much of the digestive system at the electron microscope level. Individual organs are not considered as single entities; the emphasis is on the various types of epithelial cell from 